\title{
La población inmigrante calificada colombiana residente en Estados Unidos ${ }^{1}$
}

\author{
The Skilled Colombian Immigrant \\ Population Residing in the United States
}

\section{A população imigrante qualificada colombiana residente no Estados Unidos}

\section{Rosa Emilia Bermúdez Rico ${ }^{2}$}

Profesora investigadora de la Universidad del Valle, Cali, Colombia

rosa.bermudez@correounivalle.edu.co

1 Este artículo es un resultado parcial de la investigación: "La población inmigrante calificada colombiana en Estados Unidos: características sociodemográficas e inserción laboral”, realizada por la autora durante el año 2013, con el apoyo del Centro de Documentación e Investigación Socioeconómica (CIDSE) de la Universidad del Valle, Cali, Colombia.

2 Magíster en Sociología. Doctora en Estudios de Población. 


\title{
Resumen
}

En este artículo se caracteriza la población colombiana altamente calificada residente en Estados Unidos: presenta una detallada descripción sociodemográfica e identifica las tendencias que caracterizan a esta población entre 2000-2011, a partir de la información disponible en The American Community Survey . El análisis muestra el dinamismo alcanzado por este flujo migratorio; señala una mayor y más calificada participación de las mujeres, y discute el lugar que ocupa en la movilidad calificada Sur-Norte.

Palabras clave: migración calificada; colombianos en Estados Unidos; flujos Sur-Norte.

\begin{abstract}
In this article, the highly qualified Colombian population resident in the United States is characterized. Based on the information available at The American Community Survey, it presents a detailed socio-demographic description and identifies trends that characterize this population between 2000-2011. The analysis shows the dynamism achieved by this migrational flux; indicates a greater and more qualified participation of women and discusses the place taken by it in the South-North skilled mobility.
\end{abstract}

Keywords: skilled migration; Colombians in the United States; South-North flows.

\section{Resumo}

Este artigo caracteriza a população colombiana altamente qualificada, residente nos Estados Unidos. Apresenta uma descrição sociodemográfica detalhada, e salienta as tendências que identificam essa população entre 2000-2011, a partir da informação disponível em "The American Community Survey". A análise mostra o dinamismo atingido por este fluxo migratório; assinala uma alta qualificação da participação das mulheres, discutindo o lugar que ocupa na mobilidade qualificada Sur-Norte.

Palavras-chave: migração qualificada; colombianos nos Estados Unidos; fluxos Sur-Norte.

3 Las bases de datos The American Community Survey (ACS) 2000, 2005 y 2011 suministradas para la realización de esta investigación por: Steven Ruggles, J. Trent Alexander, Katie Genadek, Ronald Goeken, Matthew B. Schroeder, and Matthew Sobek. Integrated Public Use Microdata Series, Internacional -IPUMS-, Minneapolis: University of Minnesota

(C) (i) Este trabajo está bajo la licencia Creative Commons Attribution 3.0 


\section{Introducción}

La migración de personas con alta calificación se ha intensificado en las últimas décadas en todas las regiones del mundo y en la actualidad constituye uno de los patrones que caracteriza la movilidad global contemporánea. Los migrantes calificados se definen como aquellas personas que han logrado una educación correspondiente a estudios de tercer y cuarto nivel (profesional y posgrado), residentes en un país distinto del que nacieron (SELA 2009; Lozano y Gandini 2011; Esteban 2011; Coloma 2012; Bermúdez 2012; Bermúdez 2014).

La migración calificada incluye diversos grupos de personas según la razón de la movilidad calificada: estudiantes, científicos, académicos, trabajadores ejecutivos, técnicos y profesionales asalariados e independientes, empresarios, entre otros, que configuran un heterogéneo colectivo. Al respecto, Bermúdez ha sugerido una tipología de los migrantes calificados que da cuenta de esta heterogeneidad, incorporando algunas de las dimensiones analíticas que cobran importancia en la caracterización de estos flujos migratorios, entre los que se destacan: la razón de la migración, el tipo de recursos que apoyan la movilidad, el estatuto legal con el que se ingresa al país receptor, la caracterización individual y familiar de la migración y, el tipo de inserción laboral a la que se accede en el país receptor (Bermúdez 2010).

En tal sentido, podemos afirmar que los diversos y complejos procesos que caracterizan las sociedades contemporáneas han favorecido la conformación de significativos y considerables acumulados (stocks) de inmigrantes calificados en las sociedades de destino, en las últimas décadas. El acumulado de emigrados que residen en los países receptores constituye universos heterogéneos, en los que confluyen diversos tipos de movilidades de la población con estudios superiores; los flujos de migrantes calificados consideran diversas motivaciones e involucran un sinnúmero de circunstancias, configurando, de esta forma, un proceso multifacético y complejo.

Investigaciones recientes coinciden en señalar que en las últimas décadas se ha presentado un significativo incremento del acumulado de migrantes con estudios superiores, tanto en términos absolutos como relativos, respecto a los migrantes con niveles educativos bajo y medio. Así mismo, se ha señalado que este incremento de migrantes calificados se ha caracterizado, en términos demográficos, por una mayor participación de mujeres y jóvenes (Docquier, Lowell y Marfouk 2009; Clemens 2009; Esteban 2011, Bermúdez 2012). Los estimativos señalan que el acumulado de migrantes de alta calificación y con 25 años y más, residentes en los países de la Organización para la Cooperación y el Desarrollo Económico (OCDE) tuvo un incremento de $111,3 \%$ entre 1990 y 2007, pasando de 12.237.000 a 25.859.000 personas con este perfil. Los países de América Latina presentan el mayor incremento entre las regiones en el mundo con un aumento de $155,2 \%$ en este mismo período $y$, entre estos se destacan los países andinos (Colombia, Perú, Ecuador, Bolivia y Venezuela) con un incremento de $161,3 \%$ (SELA 2009).

En diversas investigaciones recientes se ha señalado que la migración internacional colombiana es altamente selectiva en cuanto al nivel educativo (Gaviria 2004; Guarnizo 2008; Bermúdez 2012). Estas investigaciones han destacado 
que los flujos migratorios colombianos contemplan una significativa y creciente participación de personas altamente calificadas. En tal sentido, se ha puesto de manifiesto la importancia que este fenómeno viene ganando en la realidad del país y se ha hecho necesario e importante dar cuenta de este fenómeno global en el contexto específico como se presenta en la sociedad colombiana.

Estimaciones recientes han planteado que el equivalente a $10 \%$ de la población con estudios de tercer nivel en Colombia ha emigrado al exterior. Estimativo que coloca a Colombia como el país sudamericano con el mayor nivel de exportación de personas calificadas en la actualidad (SELA 2009). De este $10 \%$ de profesionales exportados como mano de obra calificada, $5 \%$ tiene como destino los Estados Unidos de América. De ahí la importancia que adquiere el análisis del acumulado de inmigrantes calificados colombianos residentes en Estados Unidos.

El análisis de la población calificada colombiana residente en Estados Unidos que presentamos se fundamenta en la información capturada por la American Community Survey (ACS) correspondiente a los años 2000, 2005 y 2011. La ACS es una encuesta realizada por la oficina del censo de Estados Unidos, fundamentada en un diseño probabilístico y estratificado, representativo a escala nacional. Para el análisis realizado, los inmigrantes calificados se establecieron a partir de la selección de casos utilizando la siguiente definición operativa: población nacida en Colombia e India residente en Estados Unidos con nivel educativo correspondiente a título universitario o más y con edad igual a 25 años o mayor. Con esta operativización nos acogemos a la definición reportada por la literatura especializada (Batalova y Fix 2008; Lozano y Gandini 2011; Bermúdez 2010; Bermúdez 2012).

La selección de los grupos definidos, colombianos e indios, tiene como propósito el análisis comparativo de la migración calificada de estos dos países. Se han seleccionado los inmigrantes nacidos en Colombia dada su caracterización como país andino y por presentar un importante crecimiento en sus flujos migratorios calificados, según ha demostrado la literatura más reciente publicada sobre el tema (Docquier, Lowell y Marfouk 2009; Lozano y Gandini 2011; Coloma 2012). De otro lado, para el ejercicio comparativo y de contraste se han seleccionado los inmigrantes nacidos en India, en razón a la alta cualificación de su flujo migratorio, caracterización que ha sido ampliamente reportada por la literatura especializada (Saxenian 2005; Khadria 2007). De igual forma, el análisis de las tendencias de estos flujos de inmigrantes se coloca en referencia con la población nacida en Estados Unidos clasificada en dos grandes grupos diferenciados: blancos no hispanos y negros no hispanos.

El nivel de escolaridad ha sido establecido como el principal atributo para la clasificación de los migrantes calificados (Pellegrino 2001; Coloma 2012). Desde la perspectiva de la acumulación de capital humano para la migración calificada se considerarían como indicadores de interés: el número de años de estudio, la experiencia laboral y las posibilidades que se tienen para desarrollar el proyecto migratorio. De estas opciones, la fuente de datos que hemos utilizado permite medir el número de años de escolaridad y, por tanto, utilizaremos este como indicador principal en la definición operativa; la formación de tercer nivel y más, 
en términos de la variable de nivel educativo resulta equivalente a tener el título de bachelor y más.

Se ha estructurado el documento de la siguiente forma: tras la introducción presentada, se discute el estatus que presenta Estados Unidos como el principal país receptor de migrantes calificados en la actualidad; seguidamente, se presentan los principales indicadores que permiten establecer las tendencias más importantes del acumulado de inmigrantes calificados colombianos en Estados Unidos. Posteriormente, se establecen algunos de los patrones sociodemográficos de la población inmigrante calificada colombiana en Estados Unidos, y se discuten las principales características de esta población en relación con el capital humano y el capital social. Para finalizar se sugieren algunas conclusiones.

\section{Estados Unidos como país receptor de migrantes calificados}

La emigración mundial presenta una fuerte concentración en un solo destino: Estados Unidos. Este patrón migratorio global se observa de manera predominante en América Latina y el Caribe. A partir de 1970 se presenta un cambio de patrón migratorio en Estados Unidos que pasó del predominio de flujos europeos a los latinoamericanos, caribeños y asiáticos (Sassen 1993). En el marco de este nuevo patrón migratorio, los nacidos en el extranjero residentes en Estados Unidos se han incrementado sustancialmente en las últimas décadas, pasando de 20 millones en 1990 a 40 millones en 2010 (Martín y Midgley 2010). De tal forma que, entre 1990 y 2004, América Latina y Asia aportaron cada uno una quinta parte de todos los inmigrantes que entraron a Estados Unidos (Ariza y Portes 2007).

De igual forma, Estados Unidos es el país de destino que en mayor medida concentra los flujos de migración calificada de los diferentes países y regiones del mundo. Este país presenta una significativa demanda de personas altamente especializadas y resulta ser el país más atractivo para los migrantes de mayor calificación y más altos niveles educativos. En términos generales, se ha explicado esta atracción en el dinamismo del sistema productivo de los Estados Unidos; en la flexibilidad de su política migratoria que ha considerado visas especiales para facilitar flujos de fuerza de trabajo especializada según perfiles productivos y laborales específicos; y en el déficit de estudiantes en tercer y cuarto nivel para áreas de las ingenierías y alta tecnología (Pellegrino y Martínez 2001; Saxenian 2006; Fiori y Koolhaas 2012).

En particular, la movilidad internacional por razones de estudio, considerada como la puerta de entrada de la migración calificada de tipo académico, constituye un flujo ilustrativo del predominio de Estados Unidos como país de destino de estos flujos. De acuerdo con los datos del Instituto de Estadística de la Organización de Naciones Unidas para la Educación y la Cultura (Unesco) sobre la movilidad de estudiantes de tercer y cuarto nivel, se estima que en 2005 y 2010 Estados Unidos recibió $20 \%$ de los estudiantes móviles internacionales de tercer y cuarto nivel. Este porcentaje duplica al Reino Unido, el segundo país receptor de este tipo de movilidad, que recibió 10\% de los estudiantes móviles internacionales, en el mismo período (Bermúdez 2015). 
En el 2011, la población total de Estados Unidos, nativos e inmigrantes, ascendía a 311.591.919 personas. De este total, la población calificada, es decir con titulación universitaria o más y con 25 años y más, abarcaba 58.996.112 personas, equivalente a $18,9 \%$. Al observar de manera desagregada, se identifica que entre la población nacida en Estados Unidos los calificados representan 18,2\%, proporción levemente inferior al porcentaje general de calificados en el país. En tanto que, entre los inmigrantes, los calificados representan $23,5 \%$. Esta brecha en la proporción de calificados entre nativos e inmigrantes indica el carácter altamente selectivo de la migración hacia Estados Unidos; no obstante, esa selectividad presenta importantes diferencias según la región de origen $\mathrm{y}$, más significativamente, dependiendo del país de nacimiento como se analiza a continuación.

Es importante resaltar que en este contexto, la migración calificada a Estados Unidos proveniente de los países asiáticos se ha constituido en un referente paradigmático de estos flujos migratorios en las sociedades contemporáneas, en la medida en que todos sus indicadores muestran a los inmigrantes calificados asiáticos en un lugar privilegiado en la sociedad estadounidense; a su vez, esta es la experiencia más importante e influyente de movilidad de talentos en la sociedad global contemporánea, como lo ha resaltado AnnaLee Saxenian (2006) en su análisis de la experiencia de redes empresariales y entrenamiento profesional de los ingenieros asiáticos en Silicon Valley. En contraste, poco conocemos acerca de la caracterización sociodemográfica y de los procesos de integración social y laboral de los inmigrantes calificados sudamericanos y, menos aún, de los colombianos calificados en Estados Unidos. Este es pues el propósito general del análisis que desarrollamos a continuación.

\section{Acumulado de inmigrantes calificados colombianos en Estados Unidos}

El acumulado de inmigrantes colombianos residentes en Estados Unidos ha aumentado de manera sostenida en la última década, pasando de 473.525 a 675.668 personas, entre el 2000 y el 2011. Al observar, específicamente, el acumulado de migrantes colombianos calificados residentes en Estados Unidos -25 años de edad o más y que cuentan con un título de licenciatura (profesional) o más-, se identifica que ha tenido mayor (o más dinámico) crecimiento poblacional en el mismo período de referencia, tanto en términos absolutos como relativos. En términos absolutos se tiene que en el 2000, los colombianos calificados se contabilizaban en 82.864 y, en el 2011, se había duplicado su número, llegando a 167.841 personas, lo que indica un crecimiento significativamente superior al crecimiento del flujo en general. Este incremento del flujo de la migración calificada ha implicado que los colombianos con este nivel educativo pasaran de representar $17,5 \%$ a $24,8 \%$ respecto a la población total de colombianos residentes en Estados Unidos, en ese período (tabla 1).

En dos sentidos resulta importante subrayar el dinámico incremento en el número de colombianos con alto nivel de escolaridad residentes en Estados Unidos. De un lado, en términos comparativos, la proporción de colombianos calificados residentes en Estados Unidos es mucho mayor que su equivalente residente en Colombia, ya que en el 2005, los colombianos mayores de 25 años 
Tabla 1. Población calificada residente en Estados Unidos según país de nacimiento y condición étnico-racial, 2000 y 2011

\begin{tabular}{|c|c|c|c|c|c|c|c|c|}
\hline \multirow{3}{*}{$\begin{array}{l}\text { Característica } \\
\text { Año } \\
\text { Población total }\end{array}$} & \multicolumn{2}{|c|}{$\begin{array}{l}\text { Nacidos en } \\
\text { Colombia }\end{array}$} & \multicolumn{2}{|c|}{$\begin{array}{l}\text { Nacidos en } \\
\text { India }\end{array}$} & \multicolumn{2}{|c|}{$\begin{array}{c}\text { Nacidos en BUA } \\
\text { blancos no } \\
\text { hispanos }\end{array}$} & \multicolumn{2}{|c|}{$\begin{array}{c}\text { Nacidos en EUA } \\
\text { negros no } \\
\text { hispanos }\end{array}$} \\
\hline & 2000 & 2011 & 2000 & 2011 & 2000 & 2011 & 2000 & 2011 \\
\hline & 473.525 & 675.668 & 1.092 .189 & 1.879 .671 & 181.929 .803 & 188.000 .565 & 29.385 .421 & 34.798 .423 \\
\hline Hombres & 194.636 & 286.133 & 599.026 & 987.187 & 89.034 .558 & 92.647 .455 & 13.519.942 & 16.612 .501 \\
\hline Mujeres & 278.889 & 389.536 & 493.163 & 892.486 & 92.895 .245 & 95.353.110 & 15.865 .479 & 18.185.922 \\
\hline $\begin{array}{l}\text { \% Calificados respecto } \\
\text { al total }\end{array}$ & 17,5 & 24,8 & 57,1 & 65,0 & 18,5 & 22,1 & 7,8 & 10,4 \\
\hline Población calificados & 82.864 & 167.841 & 623.732 & 1.222 .288 & 33.633 .947 & 41.582 .505 & 2.296 .778 & 3.616 .056 \\
\hline Licenciatura & 48.311 & 102.416 & 268.177 & 542.488 & 21.758 .615 & 26.195 .696 & 1.589 .522 & 2.356 .738 \\
\hline Maestría & 18.398 & 39.898 & 234.139 & 498.298 & 8.095 .801 & 10.946 .798 & 531.421 & 1.004392 \\
\hline Estudios profesionales & 10.806 & 18.909 & 64.270 & 100.292 & 2.575 .871 & 2.826 .432 & 11.765 & 147.1.44 \\
\hline Doctorado & 5.349 & 6.618 & 57.146 & 81.210 & 1.203 .660 & 1.613 .579 & 64.070 & 107.782 \\
\hline $\begin{array}{l}\text { \% Calificados hombres } \\
\text { respecto al total de } \\
\text { hombres }\end{array}$ & 18,9 & 25,3 & 63,4 & 68,6 & 19,6 & 22,2 & 6,8 & 8,3 \\
\hline $\begin{array}{l}\text { Población de } \\
\text { calificados }\end{array}$ & 36.858 & 72.493 & 379.882 & 676.991 & 17.425 .784 & 20.583 .212 & 918.600 & 1.377 .383 \\
\hline Licenciatura & 16.885 & 42.611 & 137.518 & 276.348 & 11.000 .240 & 12.896 .994 & 643.701 & 941.443 \\
\hline Maestría & 11.585 & 19.318 & 156.211 & 286.594 & 3.934 .249 & 4.902 .044 & 200.274 & 326.791 \\
\hline Estudios profesi & 5.484 & 7.145 & 37.079 & 56.385 & 1.641 .455 & 1.777 .358 & 47.950 & 63.239 \\
\hline Doctorado & 2.904 & 3.419 & 49.079 & 57.664 & 849.840 & 1.006 .816 & 26.675 & 45.910 \\
\hline $\begin{array}{l}\text { \% Calificadas mujeres } \\
\text { respecto al total de } \\
\text { mujeres }\end{array}$ & 16,5 & 24,5 & 49,4 & 61,1 & 17,4 & 22,0 & 8,7 & 12,3 \\
\hline $\begin{array}{l}\text { Población de } \\
\text { calificadas }\end{array}$ & 46.006 & 95.348 & 243.850 & 545.297 & 16.208 .163 & 20.999.293 & 1.378 .178 & 2.238 .673 \\
\hline Licenciatura & 31.426 & 59.805 & 130.659 & 266.140 & 10.758.375 & 13.298 .702 & 945.821 & 1.415 .295 \\
\hline Maestría & 6.813 & 20.580 & 77.928 & 211.704 & 4.161.552 & 60.44 .754 & 331.147 & 677.601 \\
\hline Estudios profesionales & 5.322 & 11.764 & 27.191 & 43.907 & 934.416 & 1.049 .074 & 63.815 & 83.905 \\
\hline Doctorado & 2.445 & 3.199 & 8.072 & 23.546 & 353.820 & 606.763 & 37.395 & 61.872 \\
\hline
\end{tabular}

Fuente: elaboración propia a partir de American Community Survey (ACS) 2000, 2005 y 2011. Microdatos suministrados por Minnesota Population Center-IPUMS USA.

con un título profesional o más sumaban 3.384.050 personas, equivalente a 16\%, según los datos censales del 2005 (DANE 2005); mientras que el porcentaje de colombianos con este nivel educativo residentes en Estados Unidos en el mismo año era de $26,1 \%$. En tal sentido, se enfatiza en la alta selectividad de la migración colombiana a Estados Unidos y/o el alto nivel educativo que presenta la población colombiana en ese país. De otro lado, resulta importante destacar 
que durante el período analizado el incremento en la proporción de los colombianos calificados residentes en Estados Unidos supera la proporción de los altamente calificados de los blancos no hispanos nacidos en Estados Unidos, que constituye el grupo poblacional mejor posicionado en términos educativos en ese país. Así, los calificados colombianos pasan de $17,5 \%$ en el 2000 a $24,8 \%$ en el 2011, ubicándose por encima de la proporción altamente calificada de los blancos no hispanos nacidos en Estados Unidos, que alcanza solo 22,1\% en el 2011 y se ubica por encima de 10,4\% de los negros no hispanos nacidos en Estados Unidos ese mismo año. Este cambio en el patrón de calificación permite subrayar el dinamismo educativo que presentan los migrantes calificados colombianos en Estados Unidos en la última década (tabla 1).

En contraste, se tiene que la población originaria de India presenta niveles muy altos de participación de la población calificada entre los residentes en Estados Unidos, con $65 \%$ del total, ubicándose ampliamente por encima de otros países. En particular, en comparación con los calificados colombianos residentes en ese país, mientras uno de cada cuatro inmigrantes colombianos resulta altamente calificado, entre los indios dos de cada tres se clasifican como altamente calificados (tabla 1).

De igual forma resulta interesante subrayar que en todos los acumulados de migrantes calificados considerados se constata el mayor dinamismo presentado por la población de mujeres calificadas comparativamente con el de los hombres calificados. Así, entre 2000 y 2011, el número de mujeres calificadas se duplica en todos los casos analizados, en tanto la población calificada de hombres crece de manera más moderada sin alcanzar los niveles de las mujeres. Para la población de mujeres calificadas nacidas en Estados Unidos, tanto blancas no hispanas como negras no hispanas, se presenta el mismo patrón de mayor dinamismo de las mujeres comparativamente con la población de calificados hombres nacidos en Estados Unidos, aunque con ritmos mucho más moderados con respecto a los extranjeros (tabla 1). En suma, se puede afirmar que, en la última década, la población colombiana altamente calificada residente en Estados Unidos es proporcionalmente mayor, respecto de la que permanece en el país; también es superior respecto de la población calificada de los nacidos en Estados Unidos blancos no hispanos. Sin embargo, esta proporción de calificados colombianos residentes en Estados Unidos se ubica en un nivel muy distante de los inmigrantes calificados originarios de India; siendo este un flujo de migrantes altamente calificado desde hace varias décadas.

Algunas de las investigaciones que han examinado la participación de los migrantes de colombianos calificados en los acumulados en diversos países de destino han señalado una alta selectividad en los flujos migratorios colombianos. El análisis realizado por Guarnizo señala que el nivel de escolaridad de la población colombiana residente en Londres es igual al de los británicos londinenses, en tanto "el 53\% de las colombianas en Londres tiene títulos universitarios o de posgrado y el 34\% de los hombres" (Guarnizo 2008, 46). De igual forma, el análisis realizado por Bermúdez (2012) de la población colombiana residente en México caracteriza este flujo como el más altamente calificado con $76 \%$ de la población de más de 25 años y con estudios de tercer y cuarto nivel, ubicándose 
muy por encima de europeos, norteamericanos y asiáticos, lo que resulta sumamente significativo en términos de selectividad migratoria para este país.

Aunque el porcentaje de $24 \%$ de calificados colombianos residentes en Estados Unidos es comparativamente menor que la proporción de calificados señalada por Guarnizo (2008) para Londres y por Bermúdez (2012) para México, el caso de Estados Unidos cobra importancia dado el amplio volumen de profesionales que contempla este flujo migratorio que ascendía a 167.841 personas en el 2011 (tabla 1). Si comparamos el volumen de población calificada colombiana que residía en Estados Unidos en el 2005, estimada en 147.896 personas, con la residente en el país, estimada en 3.140.452 según el censo del 2005 (DANE 2005), resulta que la población calificada nacida en Colombia que se encuentra en Estados Unidos representa casi $5 \%$ de su equivalente residente en Colombia. Este importante volumen de profesionales concentrados en un solo país constituye un significativo referente de análisis para la comprensión del flujo de migrantes calificados colombianos en la actualidad.

\section{Caracterización de la población inmigrante calificada en Estados Unidos}

En este apartado se describen y analizan las características de la población colombiana residente en Estados Unidos que cuenta con tercer y cuarto nivel educativo, en los años 2005 y 201l. En el tercer nivel educativo se consideran aquellas personas que han obtenido un título de licenciatura -pregrado-y en el cuarto nivel educativo las que cuentan con título de maestría, estudios de posgrado y de doctorado.

La caracterización que presentamos indaga acerca de aspectos centrales del debate actual sobre la migración calificada contemporánea, tales como la composición por sexo y la tendencia a la feminización de la migración calificada, la permanencia o retorno de los migrantes calificados que establece el carácter circulante o la pérdida de talentos en las sociedades contemporáneas, entre otros. Este criterio se articula con la disponibilidad de la información suministrada por la American Community Survey y, por tanto, con las condiciones reales de acceder a información para analizarla. En el análisis de las principales características de los inmigrantes calificados se han considerado los siguientes ámbitos de interés e importancia: características sociodemográficas, estructura educativa y capital humano y social.

\subsection{Tendencia a la feminización de la migración calificada}

En la composición por sexo de la población calificada cobra importancia la participación de las mujeres en los acumulados (stocks) de emigrados de los países de origen considerados. Entre 2005 y 2011, la tendencia fue a una mayor participación de las mujeres y, en algunos casos, resultó ser la mayoría. Esta tendencia y patrón migratorio coincide con lo señalado por la literatura reciente, que ha caracterizado la migración calificada contemporánea por una creciente participación de las mujeres (Docquier, Lowell y Marfouk 2009; Clemens 2009; Esteban 2011). En el marco de esta tendencia general resulta interesante precisar algunas dinámicas específicas como se señala a continuación. 
Las mujeres inmigrantes calificadas colombianas residentes en Estados Unidos se destacan por una mayor y sostenida participación pasando de representar $54,1 \%$ en el 2005 a 56,9\% en el 2011 (tabla 2). En contraste, en la población emigrada de India, aunque las mujeres calificadas presentan un ligero incremento en el período analizado, los hombres han conservado una participación mayoritaria que se mantiene en $55,2 \%$ en el 2011.

Tabla 2. Características de la población inmigrante calificada de 25 años y más, residente en Estados Unidos, según país de origen, 2005 y 2011

\begin{tabular}{|c|c|c|c|c|c|c|c|c|}
\hline \multirow{3}{*}{$\begin{array}{l}\text { Característica } \\
\text { Año }\end{array}$} & \multicolumn{8}{|c|}{ País de origen } \\
\hline & \multicolumn{2}{|c|}{ Colombia } & \multicolumn{2}{|c|}{ India } & \multicolumn{2}{|c|}{$\begin{array}{l}\text { PUA blancos } \\
\text { no hispanos }\end{array}$} & \multicolumn{2}{|c|}{$\begin{array}{l}\text { EUA negros } \\
\text { no hispanos }\end{array}$} \\
\hline & 2005 & 2011 & 2005 & 2011 & 2005 & 2011 & 2005 & 2011 \\
\hline Hombres & 45,9 & 43,1 & 56,4 & 55,2 & 50,7 & 49,0 & 40,1 & 36,5 \\
\hline Mujeres & 54,1 & 56,9 & 43,6 & 44,8 & 49,3 & 51,0 & 59,9 & 63,5 \\
\hline Total & 100,0 & 100,0 & 100,0 & 100,0 & 100,0 & 100,0 & 100,0 & 100,0 \\
\hline 25-44 años de edad & 59,9 & 49,4 & 65,9 & 62,4 & 43,9 & 36,1 & 52,1 & 40,7 \\
\hline 45-64 años de edad & 34,2 & 41,7 & 29,6 & 28,4 & 42,3 & 43,4 & 38,5 & 43,0 \\
\hline 65 y más años de edad & 5,9 & 8,8 & 4,5 & 9,2 & 13,8 & 20,5 & 9,4 & 16,3 \\
\hline Total & 100,0 & 100,0 & 100,0 & 100,0 & 100,0 & 100,0 & 100,0 & 100,0 \\
\hline Edad media & 43 & 46 & 41 & 43 & 48 & 51 & 45 & 49 \\
\hline
\end{tabular}

Fuente: elaboración propia a partir de American Community Survey (ACS) 2005 y 2011. Microdatos suministrados por Minnesota Population Center-IPUMS USA.

La configuración diferenciada por sexos de los acumulados de inmigrantes calificados cobra importancia en la construcción del perfil migratorio en dos sentidos. De un lado, por parte de los países en desarrollo o de origen, con la adopción de estrategias de "producción de fuerza de trabajo" que están orientadas a la exportación de mano de obra y, de otro lado, por parte de los países desarrollados o de destino que han adoptado estrategias para la búsqueda activa de fuerza de trabajo especializada para resolver las carencias de sus economías o potencializar ámbitos de interés. A manera de ilustración de este fenómeno contemporáneo, se han identificado los flujos de mujeres migrantes calificadas en el campo de la sanidad y la salud, con una amplia participación de enfermeras y profesionales del "cuidado", que se han establecido como redes globales entre países del Sur y del Norte (Yeates 2010).

En tal dirección, nuestro análisis permite señalar que el acumulado de calificados colombianos en Estados Unidos presenta una tendencia a la feminización, en tanto el de India, aunque comparte esta tendencia general, conserva una mayor participación masculina. El predominio de los hombres entre los emigrados indios en Estados Unidos se ha asociado con la significativa participación de ingenieros y científicos de sistemas y software movilizados inicialmente para estudiar y que posteriormente se han insertado laboralmente en las grandes empresas de tecnología en Silicon Valley (Saxenian 2005; Saxenian 2006; Khadria 2007). Con respecto a la significativa participación de mujeres en el flujo de calificadas colombianas no disponemos de investigaciones que hayan centrado su atención al respecto y el análisis aquí presentado puede contribuir con este propósito. 
En cuanto a la población calificada nacida en Estados Unidos es importante señalar que comparte la tendencia general a una mayor participación de las mujeres; es preciso subrayar la alta participación de las mujeres negras no hispanas respecto a los hombres de iguales características en el período analizado, 59,9\% en 2005 y 63,5\% en 2011 (tabla 2).

\subsection{Estructura por edades de la población de emigrados calificados}

Con el propósito de establecer la estructura por edad de la población calificada residente en Estados Unidos se definieron tres rangos de edad a partir de los 25 años, límite inferior de acuerdo con la definición operativa establecida, y se estimó la edad media en años según país de origen. Con estas categorías se hizo el procesamiento de la información disponible. Algunos de los patrones y tendencias identificados se describen a continuación.

En el 2005, los acumulados de emigrados tienen mayor participación relativa en el grupo de edad de 25 a 44 años con respecto a la población calificada nacida en Estados Unidos, en los dos grupos establecidos como población de referencia. Los colombianos calificados en este rango de edad representan 59,9\% en el 2005 , mientras que los emigrados indios en este rango de edad concentran $65,9 \%$. En los otros dos grupos de edad, de 45 a 64 y de 65 años y más, la población emigrada tiene una participación relativa menor que la de referencia nacida en Estados Unidos. Esta estructura de edades indica una población de emigrados calificados un poco más joven que los calificados nacidos en Estados Unidos. En este contexto, el acumulado de inmigrantes calificados indios presenta la población más joven, con una edad promedio de 41 años, con respecto a la edad promedio de los inmigrantes colombianos, de 43 años (tabla 2).

En el 2011, los emigrados calificados de Colombia del grupo de edad de 25 a 44 años disminuyen su participación relativa de manera significativa con respecto al 2005 y tienden a ubicarse mucho más cercanos a la participación de los grupos de referencia nacidos en Estados Unidos, principalmente en el grupo de 45 a 64 años. En tanto, los emigrados calificados de India mantienen una importante diferencia en la participación de los más jóvenes conservando 62,4\% de los emigrados en el rango de 25 y 44 años edad (tabla 2).

Por tanto, en el período analizado se mantiene entre los emigrados calificados la característica de constituir una población más joven al compararse con la población calificada nacida en Estados Unidos, aunque con mayor proximidad en la estructura por edades entre los emigrados colombianos y los nacidos en Estados Unidos, en contraste con los emigrados calificados provenientes de India que presentan un perfil etario más joven. Esta tendencia puede estar asociada, de un lado, con un mayor dinamismo en los flujos migratorios de población de menor edad entre los indios con respecto a los colombianos y, de otro lado, con un mayor retorno de la población calificada india en edades tempranas y una mayor permanencia de los inmigrantes calificados colombianos en Estados Unidos en edades avanzadas.

No obstante, si se compara la estructura por edad de los inmigrantes calificados colombianos en Estados Unidos con la población calificada en España o México, 
se advierte que se trata de una población en edades avanzadas, en tanto el rango modal se ubica en España en 30-34 años de edad (Fiori y Hoolkaas 2012) y en México en 35-39 (Bermúdez 2012).

Este perfil etario de los inmigrantes calificados colombianos en Estados Unidos posiblemente está asociado, de un lado, con la mayor antigüedad del flujo migratorio hacia ese país de destino con respecto a los flujos emergentes señalados $\mathrm{y}$, de otro, con la movilidad realizada en una etapa más tardía del ciclo vital tras un proceso de calificación escolar y laboral más avanzado en la sociedad de origen.

\subsection{Conyugalidad y número de hijos de la población inmigrante calificada residente en Estados Unidos}

Para una aproximación a la situación familiar de la población de los inmigrantes calificados residentes en Estados Unidos se ha considerado el estado civil y el número de hijos.

Los inmigrantes calificados colombianos presentan una distribución en las categorías de su estado civil que se aproxima bastante a la población calificada blanca no hispana nacida en Estados Unidos. En el 2011, predominan los casados con una participación de $65 \%$; en segundo lugar se ubican los nunca casados -solteros- que representan $14,3 \%$ y, en tercer lugar, los divorciados con 12,8\%. Los emigrados indios, presentan un porcentaje mayor de casados (82\%) y menor de solteros (10,3\%). La distribución del estado civil de los emigrados colombianos se distancia de los negros no hispanos nacidos en Estados Unidos, en tanto estos presentan una proporción mucho menor de casados $(42,7 \%) \mathrm{y}$, consecuentemente, más alta de solteros (29,4\%). Estos patrones son válidos tanto para el 2005 como para el 2011 (tabla 3).

Tabla 3. Características familiares de la población inmigrante calificada de 25 años y más, residente en Estados Unidos, según país de origen, 2005 y 2011

\begin{tabular}{|c|c|c|c|c|c|c|c|c|}
\hline \multirow{3}{*}{ Característica } & \multicolumn{8}{|c|}{ Pais de origen } \\
\hline & \multicolumn{2}{|c|}{ Colombia } & \multicolumn{2}{|c|}{ India } & \multicolumn{2}{|c|}{$\begin{array}{l}\text { EUA blancos } \\
\text { no hispanos }\end{array}$} & \multicolumn{2}{|c|}{$\begin{array}{l}\text { EUA negros } \\
\text { no hispanos }\end{array}$} \\
\hline & 2005 & 2011 & 2005 & 2011 & 2005 & 2011 & 2005 & 2011 \\
\hline \multicolumn{9}{|l|}{ Estado civil } \\
\hline Casado/a con esposo/a presente & 67,9 & 65,2 & 83,1 & 82,0 & 69,2 & 61,7 & 46,2 & 42,7 \\
\hline Casado/a con esposo/a ausente & 3,3 & 3,5 & 3,8 & 3,3 & 1,1 & 1,4 & 2,3 & 2,6 \\
\hline Separado/a & 2,7 & 2,7 & 0,5 & 0,6 & 1,0 & 0,9 & 3,4 & 2,9 \\
\hline Divorciado/a & 9,2 & 12,8 & 2,1 & 2,3 & 9,6 & 9,7 & 15,2 & 16,4 \\
\hline Viudo/a & 2,0 & 1,4 & 1,5 & 1,6 & 3,5 & 4,3 & 4,7 & 6,0 \\
\hline Nunca casado/soltero/a & 14,9 & 14,3 & 9,1 & 10,3 & 15,6 & 15,3 & 28,2 & 29,4 \\
\hline Total & 100,0 & 100,0 & 100,0 & 100,0 & 100,0 & 100,0 & 100,0 & 100,0 \\
\hline \multicolumn{9}{|l|}{ Número de hijos } \\
\hline Sin hijos & 46,9 & 47,6 & 39,9 & 40,2 & 58,2 & 61,7 & 56,0 & 61,0 \\
\hline 102 hijos & 46,3 & 45,0 & 55,3 & 56,4 & 33,7 & 31,0 & 37,1 & 33,6 \\
\hline 3 o más hijos & 6,8 & 7,4 & 4,8 & 3,4 & 8,1 & 7,3 & 6,9 & 6,4 \\
\hline Total & 100,0 & 100,0 & 100,0 & 100,0 & 100,0 & 100,0 & 100,0 & 100,0 \\
\hline
\end{tabular}

Fuente: elaboración propia a partir de American Community Survey (ACS) 2005 y 2011. Microdatos suministrados por Minnesota Population Center-IPUMS USA. 
Respecto al número de hijos encontramos que, en el 201l, casi la mitad de la población de emigrados calificados colombianos no tiene hijos, 47,6\%; a diferencia de la población calificada nacida en Estados Unidos que presenta un porcentaje de $61 \%$ sin hijos, tanto para los blancos no hispanos como para los negros no hispanos (tabla 3).

\section{Capital humano y capital social de los inmigrantes calificados residentes en Estados Unidos}

El análisis de la estructura educativa de los inmigrantes calificados en Estados Unidos, así como el dominio que tienen del inglés, el tiempo de permanencia y la adquisición de la condición de ciudadanos se constituyen en indicadores importantes de distinción, competitividad y estatus en la sociedad receptora. Este conjunto de atributos y habilidades representa el capital humano y capital social de esta población.

\subsection{Estructura educativa de los inmigrantes calificados en Estados Unidos}

La distribución de los inmigrantes calificados según el grado de escolaridad alcanzado establece con mayor precisión el grado de especialización y el nivel de calificación de este acumulado de migrantes. La estructura educativa del acumulado de migrantes calificados residente en Estados Unidos según la titulación alcanzada considera la siguiente clasificación: licenciatura o bachelor según la denominación en el sistema educativo estadounidense, maestría, profesional de posgrado ${ }^{4}$ y doctorado. El procesamiento de la información disponible se realizó especificando por sexo, nivel educativo y país de origen (tabla 4).

En el 2005, de los colombianos emigrados calificados residentes en Estados Unidos $63,4 \%$ tiene formación en licenciatura, $18,8 \%$ en maestría, $14,6 \%$ tiene título profesional de posgrado y $3,2 \%$ ha alcanzado un título de doctorado. En el 2011, aunque en términos generales se mantiene esta estructura, se presenta una mayor calificación del acumulado de emigrados en tanto se tiene mayor participación de los niveles de maestría y doctorado. En ambos niveles formativos se identifica un importante dinamismo en la participación de las mujeres que incide positivamente en la calificación del acumulado en su conjunto. En el nivel de maestría que se incrementó a $23,9 \%$, las mujeres pasaron de $14,8 \%$ en el 2005 a $23,2 \%$ en el 2011, y en el nivel de doctorado que se incrementó en el 2011 a 4,4\% del total del acumulado calificado colombiano, las mujeres con este nivel formativo pasaron de $2,2 \%$ a 3,8\% del total de mujeres calificadas (tabla 4).

4 En el sistema educativo de Estados Unidos se establecen algunas titulaciones y formaciones de élite por el desempeño de funciones especiales y asociadas con una alta escolaridad de posgrado. Se clasifican entre estas: consultores y asesores de alto nivel; personas con capacidad y formación administrativa y gerencial especiales; así como personas con formación interdisciplinaria en programas formales. En términos prácticos para el análisis realizado hemos decidido mantener esta categoría independiente con el fin de tener mayor claridad en el comportamiento de las otras tres categorías del nivel educativo que considera la variable ordinal de la ACS: licenciatura, maestría y doctorado. 
Tabla 4. Distribución de la población de inmigrantes calificados residentes en Estados Unidos, según nivel de formación, sexo y país de origen, 2005-2011

\begin{tabular}{|l|l|r|r|r|r|r|r|}
\hline \multicolumn{1}{c}{$\begin{array}{c}\text { País de } \\
\text { origen }\end{array}$} & Nivel de escolaridad & \multicolumn{3}{|c|}{2005} & \multicolumn{3}{c|}{2011} \\
\cline { 2 - 7 } & & Total & Hombres & Mujeres & Total & Hombres & Mujeres \\
\hline Colombia & Licenciatura & 63,4 & 56,4 & 69,3 & 60,6 & 58,8 & 62,0 \\
& Maestría & 18,8 & 23,5 & 14,8 & 23,9 & 24,9 & 23,2 \\
& Título profesional de posgrado & 14,6 & 15,9 & 13,6 & 11,0 & 11,1 & 11,0 \\
& Doctorado & 3,2 & 4,3 & 2,2 & 4,4 & 5,2 & 3,8 \\
\hline \multirow{2}{*}{ India } & Licenciatura & 43,8 & 38,3 & 50,9 & 43,3 & 39,0 & 48,7 \\
& Maestría & 39,1 & 42,0 & 35,4 & 39,8 & 41,7 & 37,4 \\
& Título profesional de posgrado & 9,9 & 10,2 & 9,6 & 9,3 & 9,6 & 9,0 \\
& Doctorado & 7,2 & 9,5 & 4,1 & 7,5 & 9,7 & 4,9 \\
\hline \multirow{2}{*}{ Estados } & Licenciatura & 62,8 & 61,7 & 64,0 & 61,5 & 60,9 & 62,1 \\
Unidos & Maestría & 26,1 & 24,2 & 27,9 & 27,3 & 24,7 & 29,7 \\
blancos no & Título profesional de posgrado & 7,4 & 9,1 & 5,6 & 7,1 & 9,1 & 5,2 \\
hispanos & Doctorado & 3,7 & 4,9 & 2,5 & 4,1 & 5,2 & 3,0 \\
\hline \multirow{2}{*}{ Estados } & Licenciatura & 64,2 & 67,4 & 62,3 & 63,0 & 66,6 & 60,9 \\
Unidos & Maestría & 28,5 & 23,9 & 31,2 & 29,4 & 24,4 & 32,3 \\
negros no & Título profesional de posgrado & 4,5 & 5,3 & 4,1 & 4,3 & 5,0 & 3,9 \\
hispanos & Doctorado & 2,8 & 3,4 & 2,4 & 3,4 & 4,0 & 3,0 \\
\hline
\end{tabular}

Fuente: elaboración propia a partir de microdatos de American Community Survey (ACS) 2005 y 2011 suministrados por Minnesota Population Center-IMPUS USA.

En términos comparativos, esta estructura educativa es más calificada que su equivalente en el país de origen en el 2005. La población con maestría en Colombia solo alcanza $2,9 \%$ de la población calificada de los hombres y $2,5 \%$ de la población calificada de las mujeres; el nivel de doctorado entre los calificados colombianos solo representa $1 \%$ de los hombres y $0,5 \%$ de las mujeres, estimativos realizados a partir de la información censal del 2005 (Bermúdez 2012). Diferencias proporcionales que hacen necesario enfatizar en la alta selectividad y calificación de los acumulados de emigrados calificados en Estados Unidos no solo respecto al contexto de recepción sino también al de origen, dinámica central en el debate sobre la migración calificada contemporánea.

Resulta interesante subrayar que la estructura por niveles educativos de los inmigrantes colombianos presenta similitudes significativas con la estructura equivalente de la población de referencia, los calificados nacidos en Estados Unidos, tanto blancos no hispanos como negros no hispanos. Estos colectivos comparten tanto los patrones en la distribución con participaciones equivalentes así como las tendencias señaladas con respecto a la mayor calificación y el mayor dinamismo de las mujeres en este proceso, en el período analizado. Este encuentro entre patrones y tendencias en la población emigrada calificada colombiana y la calificada nacida en Estados Unidos está en mayor medida asociado a una intensificación en la calificación del colectivo de colombianos residentes en Estados Unidos que ha permitido "alcanzar" los niveles de calificación de la población estadounidense, en tanto en el 2005, el colectivo de colombianos presenta una distribución mucho menos calificada que los nacidos en Estados Unidos (tabla 4). 
En contraste, la población calificada emigrada proveniente de India presenta una estructura por niveles educativos que indica una mayor calificación y establece diferencias significativas con su equivalente colombiana y estadounidense. La mayor calificación del acumulado de calificados indios se expresa en la menor proporción del nivel de licenciatura (43,3\%) y el mayor porcentaje de población con nivel de maestría $(39,8 \%)$ y de doctorado $(7,5 \%)$ en el 2011 . Este acumulado presenta mayor estabilidad en el período analizado con variaciones muy leves en función de la tendencia hacia una mayor calificación como ha sido señalado. Comparte con los otros acumulados la tendencia a una mayor participación de las mujeres en los niveles de más calificación, aunque como ya lo hemos advertido la participación de las mujeres es menos dinámica comparativamente con el acumulado de la población calificada colombiana (tabla 4).

En este contexto, el colectivo de emigrados calificados colombianos presenta al final del período analizado una distribución en niveles educativos que la hace equivalente a la distribución de los nativos estadounidenses, pero mantiene una importante distancia del nivel de calificación que presenta el acumulado de la población originaria de India en Estados Unidos.

\subsection{Dominio del idioma inglés, permanencia y ciudadanía}

El dominio y la fluidez del inglés por parte de los inmigrantes en Estados Unidos han sido señalados como factor estratégico en el proceso de integración social y en el desempeño ocupacional. El dominio del inglés constituye un factor de selectividad para el acumulado de emigrados calificados $\mathrm{y}$, al mismo tiempo, no contar con esta competencia o habilidad constituye un factor de desventaja y una eficaz barrera social para la integración. El dominio del inglés -habla bien o muy bien inglés-que presentan los inmigrantes calificados es alto en los colectivos considerados y tiende a incrementarse en el período analizado. Aunque los emigrados calificados colombianos presentan porcentajes de dominio del inglés altos, $80,8 \%$ en 2005 y $88,0 \%$ en 2011 , estos resultan más bajos que los altísimos niveles que presentan sus pares provenientes de India, 97,8\% en ambos años (tabla 5).

Con respecto al tiempo de permanencia en Estados Unidos de los inmigrantes calificados, se observa que más de la mitad había permanecido más de 10

Tabla 5. Características de la población inmigrante calificada de 25 años y más, residente en Estados Unidos, según país de origen, 2005 y 2011

\begin{tabular}{|l|r|r|r|r|}
\hline \multirow{2}{*}{\multicolumn{1}{c|}{ Característica }} & \multicolumn{2}{c|}{ Colombia } & \multicolumn{2}{c|}{ India } \\
\cline { 2 - 6 } & 2005 & \multicolumn{1}{c|}{2011} & 2005 & \multicolumn{1}{c|}{2011} \\
\hline Habla bien o muy bien inglés & 80,8 & 88,0 & 97,8 & 97,8 \\
\hline No habla o no habla bien inglés & 19,2 & 12,0 & 2,2 & 2,2 \\
\hline Ciudadana & 46,6 & 59,0 & 44,8 & 50,6 \\
\hline No es ciudadana & 53,4 & 41,0 & 55,2 & 49,4 \\
\hline 1O años o menos en USA & 48,5 & 29,6 & 49,6 & 40,5 \\
\hline Más de 10 años en USA & 51,5 & 70,4 & 51,4 & 59,5 \\
\hline
\end{tabular}

Fuente: elaboración propia a partir de American Community Survey (ACS) 2005 y 2011.

Microdatos suministrados por Minnesota Population Center-IPUMS USA. 
años en este país receptor, en el 2005; este patrón se fortalece significativamente para el colectivo de colombianos que se incrementa hasta alcanzar $70,4 \%$ con más de 10 años de permanencia, en el 2011. Esta tendencia de larga permanencia por parte de los emigrados colombianos sugiere mayor probabilidad de establecerse en Estados Unidos con respecto a los emigrados indios (tabla 5).

El estatus migratorio resulta central en el análisis de la incorporación social y laboral de los inmigrantes en la sociedad de destino, en tanto define el marco de posibilidades -legales- a las que tiene acceso el inmigrante. De esta forma, el estatus migratorio resulta ser un indicador importante en cuanto a reconocimientos de derechos y ciudadanía en las sociedades de destino. De acuerdo con la información disponible utilizamos la variable condición de ciudadanía (ciudadana y no ciudadana) para aproximarnos al estatus migratorio de la población inmigrante calificada residente en Estados Unidos.

En el 2005, se observa que menos de la mitad de los emigrados calificados había adquirido la condición de ciudadanía, en tanto, en el 201l, se invierte esta relación y más de la mitad de los emigrados han adquirido la ciudadanía estadounidense. Se establece en este período no solo la tendencia a adquirir en mayor proporción la ciudadanía por parte de este colectivo, sino un punto de inflexión en tal sentido. El patrón y la tendencia señalada resultan más significativos para Colombia con 59,0\%, y menos para India con 50,6\% de sus emigrados calificados que han adquirido la ciudadanía al 2011 (tabla 5).

\section{Conclusiones}

El carácter cuantitativo de la investigación y su enfoque en una población tan selectiva como los inmigrantes calificados residentes en Estados Unidos, en el contexto general de los flujos calificados Sur-Norte, hace necesario precisar que nos centramos en la caracterización de las principales estructuras que condensan el fenómeno social que estudiamos. De igual forma, es importante advertir que nuestro análisis, al fundamentarse en la información disponible en la ACS, tiene la ventaja de poder establecer y analizar las grandes tendencias y patrones señalados, pero igualmente está marcado por las limitaciones que esta fuente de información establece y por la delimitación estructural del fenómeno estudiado.

Un primer aspecto a subrayar es que, en 2011 , la población colombiana altamente calificada residente en Estados Unidos es proporcionalmente mayor $(24,8 \%)$, con respecto de la población altamente calificada de la población calificada de blancos no hispanos nacidos en Estados Unidos (22,1\%). Los migrantes colombianos residentes en Estados Unidos con 24,8\% de calificados se ubican en un nivel muy distante de los flujos migratorios establecidos como tipos de alta calificación, como el originario de India con $65,0 \%$.

Otra de las tendencias generales identificadas es una mayor feminización de los acumulados de inmigrantes calificados en Estados Unidos. De esta forma, el porcentaje de crecimiento de la población calificada diferenciado por sexo en el período analizado señala mayor crecimiento de la población femenina así como mayor participación de las mujeres en los acumulados de inmigrantes calificados residentes en Estados Unidos. El caso colombiano es, entre la población inmigrante, el más pronunciado, ya que presenta mayor porcentaje de participación de las mujeres 
calificadas en el acumulado, representando 54,1\% en el 2005 y alcanzando 56,9\% en el 2011.

En cuanto a la caracterización sociodemográfica de la población de inmigrantes calificados colombianos se tiene que estos responden al patrón general de edad media avanzada de la población calificada en Estados Unidos, con una edad promedio de 43 años de edad y con $65,0 \%$ casados; patrones cercanos a los que presentan los nativos calificados.

En cuanto a la estructura educativa, los inmigrantes calificados colombianos presentan una distribución por niveles educativos que se acerca bastante a la que presentan los blancos no hispanos nativos y se distancia de la de sus pares provenientes de India que se caracteriza por una estructura mucho más calificada que cualquiera de los otros grupos considerados. En el caso de la población colombiana se identifica una tendencia a mayor calificación, incrementando la participación de las personas con titulación de doctorado y maestría; incremento que está principalmente asociado con una mayor escolaridad alcanzada por las mujeres inmigrantes.

La población inmigrante calificada colombiana presenta alta proporción con dominio del inglés, $88 \%$ en el 2011, aunque este porcentaje es menor que el manifestado por sus pares indios con $98 \%$, lo que se traduce en una desventaja sustancial en un porcentaje significativo de la población calificada colombiana.

Dado que 70,2\% de la población calificada colombiana en Estados Unidos ha permanecido más de 10 años en ese país, puede sugerirse que se trata de una población que se encuentra establecida en la sociedad de destino y que la probabilidad de retorno es limitada. Esta sugerencia se fortalece si consideramos que $60 \%$ ha obtenido la ciudadanía americana.

\section{Referencias bibliográficas}

Ariza, Marina y Alejandro Portes. El país transnacional: migración mexicana y cambio social a través de la frontera. México D.F.: Instituto de Investigaciones Sociales, UNAM, 2007.

Batalova, Jeane y Michael Fix. Uneven Progress: The Employment Pathway of Skilled Inmigrants in the United States. Washington D.C.: Migration Policy Institute, 2008.

Bermúdez, Rosa. «Migración calificada e integración en las sociedades de destino». sociedad y economía, $\mathrm{n}^{\circ} 19$ (julio-diciembre de 2010): 135-150.

Bermúdez, Rosa. Migración internacional calificada por razones de estudio: colombianas en México. México, D. F.: Tesis doctoral en Estudios de Población, El Colegio de México, 2012.

Bermúdez, Rosa. «Trayectorias laborales de migrantes calificadas por razones de estudio». Estudios Demográficos y Urbanos 86, Vol. 29, nº 2 (mayo-agosto 2014): 257-299.

Bermúdez, Rosa. «La movilidad de estudiantes por razones de estudio: geografía de un fenómeno global». Migraciones Internacionales, Vol. 8, $\mathrm{n}^{\circ} \mathrm{l}$ (enero-junio 2015): 94-125.

Hixson, Lindsay, Bradford Hepler y Myoung Ouk Kim. «La población hispana: 2010». Census Bureau U.S. (septiembre 2011): 1-18. http://www.census.gov/prod/cen2010/ briefs/c2010br-05.pdf (último acceso: septiembre de 2012). 
Clemens, Michael. «Skill Flow: A Fundamental Reconsideration of SkilledWorker Mobility and Development». Human Development Research Paper 8. Nueva York: Programa de Naciones Unidas para el Desarrollo, oficina encargada del Informe sobre Desarrollo Humano, 2009. http://hdr.undp.org/en/reports/global/hdr2009/papers/HDRP_2009_08.pdf (último acceso: junio 29 de 2012).

Coloma, Soledad. «Migración calificada en América Latina: similitudes y contrastes». Andina Migrante, $\mathrm{n}^{\circ} 13$ (julio 2012): 2-14.

Docquier, Frédéric, Lindsay Lowell y Abdeslam Marfouk. «A Gendered Assessment of Highly Skilled Emigration». Populaton and Development Review 2, Vol. 35 (junio 2009). http://perso.uclouvain.be/frederic.docquier/filePDF/DataSetByGender_Aggregates.xls (última consulta: 29 junio de 2012).

Esteban, Fernando. «La movilidad de profesionales y estudiantes universitarios latinoamericanos y caribeños a países de la OCDE». Papeles de Población, $\mathrm{n}^{\circ}$ 69, 2011: 105-149.

Fiori, Nicolás y Martín Koolhaas. «Inserción laboral de los inmigrantes calificados latinoamericanos en España y en los Estados Unidos». Revista Latinoamericana de Población, Vol. 6, $\mathrm{n}^{\circ} \mathrm{ll}$ (julio-diciembre, 2012): 33-57.

Gaviria, Alejandro. «Visa USA: Fortunas y extravíos de los emigrantes colombianos en los Estados Unidos». Documento CEDE, 2004-17 (marzo 2004): 1-29.

Guarnizo, Luis. Londres latina. La presencia colombiana en la capital británica. México, D.F.: Universidad Autónoma de Zacatecas/Miguel Ángel Porrúa, 2008. Khadria, Binod. «India migración calificada a los países desarrollados, migración laboral al Golfo». En Migración y desarrollo. Perspectivas desde el Sur, coordinado por Stephen Castles y Raúl Delgado, 87-124. México D.F.: Universidad de Zacatecas, Miguel Ángel Porrúa, Secretaría de Gobernación, Organización Internacional para las Migraciones, 2007.

Lozano, Fernando y Luciana Gandini. «Migración calificada y desarrollo humano en América Latina y el Caribe». Revista Mexicana de Sociología, Vol. 73, $\mathrm{n}^{\circ} 4$ (octubre-diciembre 2011): 675-713.

Martín, Philip y Elizabeth Midgley. «Inmigración en los Estados Unidos». Population Reference Bureau, 2010. http://www.prb.org/SpanishContent/2010/ immigrationupdatel-sp.aspx (último acceso: 26 de septiembre de 2014).

Pellegrino, Adela. "¿Drenaje o éxodo? Reflexiones sobre la migración calificada». 200l. http://www.programadepoblacion.edu.uy/enlazar/doc_trı2.pdf (último acceso: marzo 30 de 2015).

Pellegrino, Adela y Jorge Martínez. «Una aproximación al diseño de políticas sobre la migración internacional calificada en América Latina». Serie Población y Desarrollo, $\mathrm{n}^{\circ} 23$ (Proyecto Regional de Población FNUAP/CELADE/División de Población de la CEPAL) (diciembre 2001): 1-60.

Sassen, Saskia. The Mobility of Labor and Capital. A Study in International Investment and Labor Flow. Nueva York: Cambridge University Press, (1993) [1988].

Saxenian, AnnaLee. «From Brain to Brain Circulation: Transnational Communities of Development». Studies in Comparative International Development, Vol. 40, $\mathrm{n}^{\circ} 2$ (verano 2005): 35-61.

Saxenian, AnnaLee. The New Argonauts. Regional Advantage in a Global Economy. Cambridge, Massachusetts, Londres: Harvard University Press, 2006. 
Sistema Económico Latinoamericano y del Caribe (SELA). La emigración de recursos humanos calificados desde América Latina y el Caribe. Perspectiva de IESALC/ UNESCO. Caracas: SELA, junio de 2009. http://www.sela.org/DB/ricsela/EDOCS/ SRed/2009/06/To23600003526-o-La_emigracion_de_personal_calificado_desde_ paises_de_ALC_-_IESAC_UNESCO.pdf (último acceso: 29 de junio de 2012).

Yeates, Nicola. «La globalización de las migraciones de enfermeras. Problemas políticos y soluciones». Revista Internacional del Trabajo, Vol. 129, n 4 (diciembre 2010): 469-488.

\section{Bases de datos}

American Community Survey (2008-2011), Steven Ruggles, J. Trent Alexander, Katie Genadek, Ronald Goeken, Matthew B. Schroeder y Matthew Sobek. Integrated Public Use Microdata Series: Version 5.0 [Machine-readable database]. Minneapolis: University of Minnesota, 2010. https://international.ipums.org/ international-action/users (último acceso: abril de 2013).

DANE. Censo Nacional de Población y Vivienda, 2005, consulta en el sistema interactivo de datos Redatam. http://190.25.231.242/cgibin/RpWebEngine.exe/Po rtalAction?\&BASE=CG2005AMPLIADO (último acceso: 30 de marzo de 2015). 